This item was submitted to Loughborough's Research Repository by the author.

Items in Figshare are protected by copyright, with all rights reserved, unless otherwise indicated.

\title{
Analysis of the vehicle as a complex system, EPSRC
}

\section{PLEASE CITE THE PUBLISHED VERSION}

https://doi.org/10.21820/23987073.2018.42

\section{PUBLISHER}

Science Impact Ltd

\section{VERSION}

VoR (Version of Record)

\section{PUBLISHER STATEMENT}

This work is made available according to the conditions of the Creative Commons Attribution 4.0 International (CC BY 4.0) licence. Full details of this licence are available at: http://creativecommons.org/licenses/ by/4.0/

\section{LICENCE}

CC BY 4.0

\section{REPOSITORY RECORD}

Dickerson, Charles, and Siyuan Ji. 2019. "Analysis of the Vehicle as a Complex System, EPSRC”. figshare. https://hdl.handle.net/2134/32651. 


\section{Impact Objective}

Address the challenge of how to use innovative modelling and simulation for rigorous design and analysis to rapidly and reliably integrate substantially increased levels of digitally-enabled functionality into the vehicle as complex system

\section{Leading the way}

Professor Charles Dickerson, David Battersby, Dr David Mulvaney, Dr Siyuan Ji and Ian Knight

highlight the importance of advanced systems engineering concepts and how their novel work is leading

the way in expanding systems engineering from its origin in defence to the commercial world

\subsection{2.}

What are your research interests and how the 'Analysis of the Vehicle as a Complex System' project?

CD: The Loughborough University research team for this research theme in the Programme for Simulation Innovation (PSi) brings unique capabilities to meet the challenges. I am the academic Principal Investigator and bring over 25 years of experience in aerospace and defence systems engineering. I am also Co-Investigator for a complementary PS research theme at Sheffield University. My focus for the past 10 years has been the development, formalisation and application of the Relational Oriented Systems Engineering Technology Tradeoff and Analysis (ROSETTA) framework, which was developed in collaboration with Professor Dimitri Mavris at the Georgia Institute of Technology, US, during 200 12. Complementing the background and capabilities of the university team are those of the industrial Principal Investigator, David Battersby, and the other engineers at Jaguar
Land Rover (LR) who have contributed to PSi.

DB: I am the Senior Manager for Software Architecture at $L L R$. I have over o years expercence in defivering systems engineering projects in automotive and s. My interest in the systems design methodologies, tools and projects at Oclaro, a tier 1 provider of high

\section{PSi project is to ensure that the best} collaborative programme organised around $\begin{array}{ll}\begin{array}{l}\text { burgeoning field of advanced automotive } \\ \text { digital systems design. }\end{array} & \text { eight research themes over the period of } \\ & \text { It aims to develop capability for }\end{array}$

DM: I am an academic Co-Investigator for PSi and a senior lecturer in embedded microelectronic systems. I was a founder of Axilica, a company that provided a novel tool flow for the rapid deployment designs on embedded platforms.

Sj: I am a research associate whose ducation was in theoretical quantum physics. I have a particular intercst
in model-based systems engineering and algorithms.

IK: I am the PSi Project manager at JLR. Before coming to JLR, I was Programm Manager for collaborative research performance optical components, modul and subsystems to the telecommunications market, and I have been involved in vario types of collaborative research projects of this kind for 25 years.

Can you explain the project's correlation with the PSi?

CD: PSi is a five-year research programm funded by ILR and the Engineering and
Physical Sciences Research Council
(EPSRC). It is a f 10 million multi-university collaborative programme organised around virtual prototyping through simulation to provide manufacturers in the UK access
to new, world-class simulation tools and processes.

DM: The 'Analysis of the Vehicle as a Complex System', is one of the eight research themes defined in PSi. The core of this research theme is to develop rigorous and innovative approaches to model-driven virtual design, analysis and integration of a vehicle as a complex system. Th significantly extends engineering capabilities for embedded microelectronic systems. The model-driven aspect of the approach uses archioy a formal relational framework to achieve the rigour of system development and to control the complexity of the systems of systems (SoS) that comprise the vehicle.

DB: Virtual integration in complex system design facilitates collaboration between the mulitisciptinary teams of the vehicle which is regarded as an SoS. This elevates critical systems engineering activities from a single discipline of the system to an SoS leve possessing multidisciplinary complexity. Achieving this capability is critical to using virtual prototyping to increase speed to
market.

\section{in} \&

Could you shed light on the benefits engineering concepts proffer?

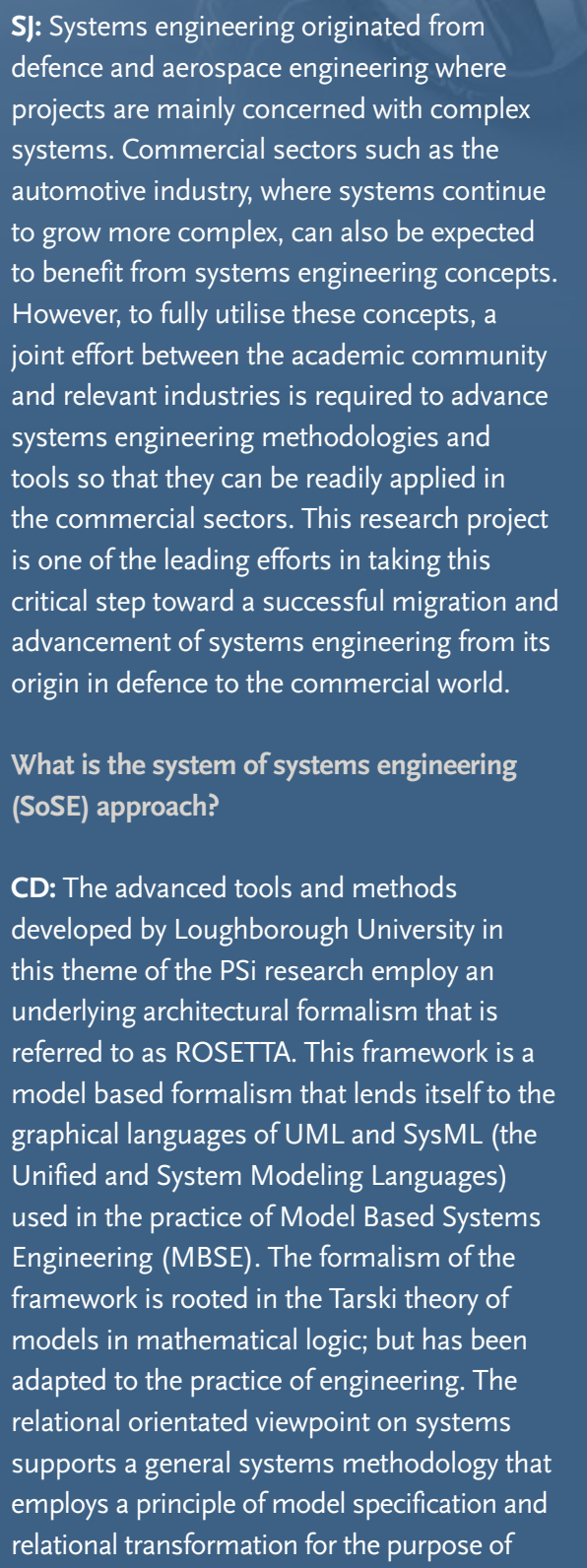

system description, analysis and design. This facility for constraint driven design has practiced by systems engineers today

How have international collaborations benefited the project?

S): Loughborough University has been involved with the Object Management Group ${ }^{\circledR}\left(\mathrm{OMC}{ }^{\circledR}\right)$, which is an internationa open membership, not-for-profit technolog standards consortium. OMG ${ }^{\circledR}$ Task Forces develop enterprise integration standards for a wide range of technologies and an even wider new cor insties. The University shares the model-based system encering community in the $\mathrm{OMG}^{\oplus}$; and OMC $\odot$ (1) 作 ROSETTA Profile. The commercialisation of software tools employ such profiles.

IK: Airbus and the US National Institute of Standards and Technology (NIST) have also been involved with Loughborough University through the OMG ${ }^{\circledR}$ in the development of the UML Profile for ROSETTA. Airbus also shares common interest in architecture optimisation.

The project is currently approaching the end of its five-year duration. Have you met you primary objectives?

CD: The project has been successful developing analysis methods that acd value to the desgin process for complex commercialisation using the UML proffle; Technology Assessment Framework has been developed to accommodate expert opinion; a relational orientated approach to model-based systems engineering and an architecture trade-off and optimisation methodology has simplify complex design spaces have been demonstrated, as have self-adaptive coordinated control architectures for vehicle off and optimisation capabilities have been initially demonstratec.

Are there plans to continue building upon the success of this project?

DB: JLR intends to use the methods developed to understand complex interactions between systems and as such ensure these systems are optimised to meet customer needs. Th will be especially valuable in the early $R \& D$ phases when it is too early to build prototypes into cars.

S: The proposed foundational facility based the UML Profle will be capable of hosting dvanced design algorithms for complex constraint-driven design problems with many design constraints and many-design variables. It will be validated using commercial quality data sets for constraint driven design trade-of analyses across multiple domains. Ultimately the facility will enable services across multiple domains for architecture optimisation and complex system design. been implemented in MATLAB@; a 


\section{Advancing the automotive industry}

A collaborative and innovative research project is making impressive headway in advancing the state of the art in complex system design and virtual prototyping in the automotive industry

Advanced automotive digital systems design and integration is a burgeoning field facing multifaceted challenges. A group of researchers is striving to equip multidisciplinary teams with the tools and methods needed to make headway in overcoming these challenges.

Professor Charles Dickerson is Principal Investigator of the 'Analysis of the Vehicle as a Complex System' project, which is a research theme in the Programme for Simulation Innovation (PSi). It began in 2013 and will conclude in 2018. 'These five years complete a second major milestone in my research over the past 10 years, which began with an appointment as the Royal Academy of Engineering Chair of Systems Engineering in 2007,' Dickerson explains. 'The first milestone was when five years of research sponsored through the Academy and others (2007-12) delivered an advanced system engineering framework and methods that have now been applied to the challenges faced in the automotive and aerospace industries.'

\section{FURTHERING THE FIELD}

PSi is co-sponsored by the Engineering and Physical Sciences Research Council (EPSRC) and Jaguar Land Rover (JLR). This research theme led by Loughborough University in the UK is one of eight in PSi. As part of PSi, 'Analysis of the Vehicle as a Complex System' is assisting in advancing the field of complex system design and prototyping in the automotive industry. To do this, the researchers involved are working to develop new tools, algorithms and methods that they hope will bring new capabilities which can support multidisciplinary teams to solve complex system design problems.

Working alongside Dickerson are CoInvestigator Dr David Mulvaney, Research Associate Dr Siyuan Ji, industrial Principal Investigator David Battersby the Senior Manager for Software Architecture at JLR, and lan Knight, who is the PSi Project Manager at JLR. 'The industrial partner JLR brings real-world challenges associated with building complex and highly interacting digital systems. The research group at Loughborough University brings advanced system engineering tools and methods that can be used to address these challenges, Knight says as he talks about the project's multidisciplinary nature.

\section{ENHANCING CAPABILITIES}

The key goal of the work is to develop advanced design and analysis capabilities for a high-interaction vehicle as a complex system. In order to achieve this, four objectives were set. These were to: develop architectural approaches to resolve issues of complexity; implement an environment that integrates simulation within the design and analysis environment; develop advanced system modelling and analysis capabilities; and apply the advances to two case studies to demonstrate the capabilities.

These case studies were concerned with (i) engine emissions reductions and (ii) vehicle motion management. 'Both case studies addressed a challenge that faces automotive manufacturers: the problem of meeting customer expectations in the context of design constraints,' explains Battersby. The case study on engine emissions reduction addressed the customer expectation for lower fuel consumption while manufacturers must adhere to emissions regulations that are becoming increasingly strict. The case study on vehicle motion management, meanwhile, looked at the longstanding research field of vehicle motion control. The outputs of this case study were coordinated control architectures that overlay onto a distributed electronic architecture.

\section{THE COMMERCIALISATION CHAPTER}

PSi is now nearing completion and, as such, the research on the Analysis of the Vehicle as a Complex System is moving into a commercialisation phase. Thanks to the project, JLR now has access to objective analysis methods that have been demonstrated to add value to the design process for complex interacting systems. Key successes achieved include the development of a family of algorithms for emission control, known as the ROSETTA axiomatic design algorithms (RADA). In addition, the UML Profile for ROSETTA (UPR) offers a foundational facility to integrate constraint driven design algorithms such as RADA. Dickerson highlights the benefits of these major milestones as 'an exploitation path for applying RADA to electronic vehicle architecture (EVA) tradeoffs and architecture optimisation has been established'. Commercialisation of UPR for future application to EVA will begin in April 2018 , which is an exciting next stage for this collaborative project team.

\section{Project Insights}

\section{FUNDING}

Engineering and Physical Sciences Research Council Grant number EP/Ko14226/1, Jaguar Land Rover

\section{ORGANISATIONS}

- Loughborough University (UK)

- Jaguar Land Rover (UK)

\section{COLLABORATIONS}

Airbus (EU)

Georgia Institute of Technology (USA)

National Institute of Standards and

Technology (USA)

Object Management Group (USA)

Sheffield University (UK)

University of Leeds (UK)

CONTACT

Charles Dickerson

Principal Investigator

T: +441509635261

E: c.dickerson@Lboro.ac.uk

W: http://gtr.rcuk.ac.uk/projects?ref=EP/ Ko14226/1

BIO

Professor Charles E Dickerson is the Royal Academy of Engineering Chair of Systems Engineering at Loughborough University. His research and design experience includes MIT Lincoln Laboratory, the Lockheed Skunkworks and Northrop Advanced Systems. He has also been Aegis Systems Engineer for the US Navy Ballistic Missile Defense Program. Dickerson is Chair of the Mathematical Formalisms Group at the $\mathrm{OMG}$ and Assistant Director for Analytic Enablers at INCOSE.

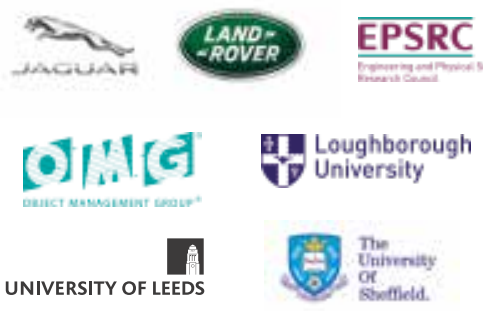

